\title{
A RARE CASE OF LATE RECURRENT GLOMUS TUMOUR OF FINGERTIP- A CASE REPORT
}

\author{
Vijayarahavan Pugalenthi1, Nellaiappan Thanappan², Jawaharlal Nehru Maheswaran', Witson Kenneth Martin ${ }^{4}$
}

1 Professor and HOD, Department of Orthopaedics and Traumatology, Madurai Medical College, Madurai, Tamilnadu. ${ }^{2}$ Associate Professor, Department of Orthopaedics and Traumatology, Madurai Medical College, Madurai, Tamilnadu. ${ }_{3}^{3}$ Assistant Professor, Department of Orthopaedics and Traumatology, Madurai Medical College, Madurai, Tamilnadu. ${ }_{4}^{4}$ Postgraduate Student, Department of Orthopaedics and Traumatology, Madurai Medical College, Madurai, Tamilnadu.

HOW TO CITE THIS ARTICLE: Pugalenthi V, Thanappan N, Maheswaran JN, et al. A rare case of late recurrent glomus tumour of fingertip- a case report. J. Evolution Med. Dent. Sci. 2018;7(17):2167-2169, DOI: 10.14260/jemds/2018/486

\section{PRESENTATION OF CASE}

A 43-year-old female presented to our OPD with complaints of severe pain over her right middle finger for past one year. She was diagnosed as a case of glomus tumour of the same fingertip and underwent excision seven years back in our institution. Patient was lost for follow-up after surgery. Detailed records about approach of surgery and post-op follow-up were not available.

Now she presented with the classical triad of localised tenderness, severe pain and cold sensitivity with history of aggravation of symptoms in cold weather, on holding cold objects in hands or after placing the hand in cold water.

On examination, Love's Pin Test and Hildreth's Sign and cold sensitivity test was found positive.

\section{X-Ray}

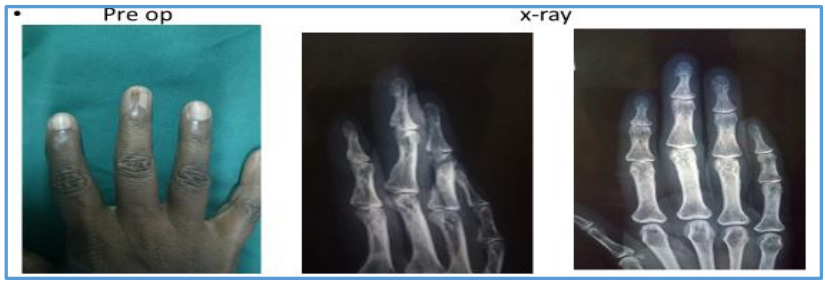

She was diagnosed as a case of recurrent glomus tumour of the fingertip, a late recurrence of more than 8 years old. She was evaluated to rule out Paronychia, Neurofibromatosis I and complex regional pain syndrome (CRPS). She was treated with excision of the entire tumour through subungual approach. It is preferred over the lateral approach, as precise and complete excision of tumour tissue is superior with this approach.

Surgery was performed under loupe magnification. Intraoperatively, we found bluish discolouration of the tumour tissue following nail removal and nail bed incision, then the entire tumour tissue was removed meticulously in toto with preservation of nail bed following which nail bed was sutured back.

'Financial or Other Competing Interest': None.

Submission 28-02-2018, Peer Review 06-04-2018,

Acceptance 12-04-2018, Published 23-04-2018.

Corresponding Author:

Witson Kenneth Martin

\#124, oasis PG Hostel,

Panagal Road, Madurai-20,

Tamilnadu.

E-mail: kenteenu@gmail.com

DOI: $10.14260 /$ jemds $/ 2018 / 486$

\section{(c) (i) $(9)$}

\section{Per-Operative Findings}
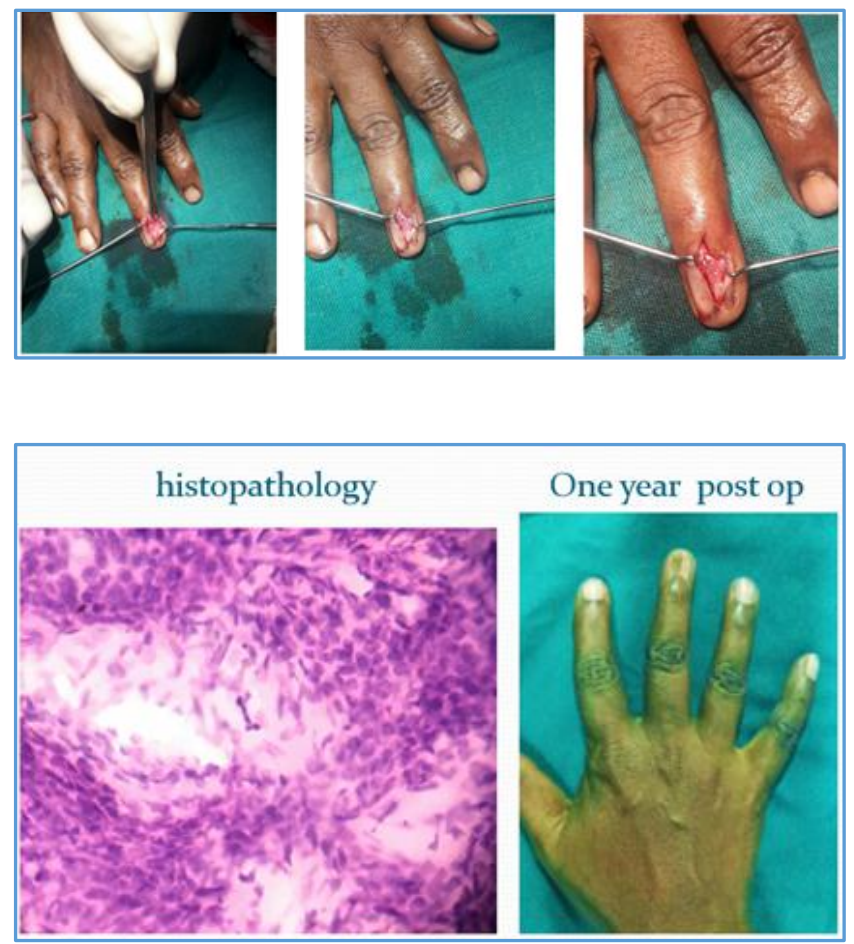

\section{PATHOLOGICAL DISCUSSION \\ Histology}

Histologically, this is a well-circumscribed lesion, characterised by solid aggregates of glomus cells around small capillary sized vessels in a myxoid or hyalinised stroma. The glomus cell is round, regular shaped with a sharply punched out rounded nucleus.

\section{Follow-Up}

Patient was asked to come for regular follow-up every month. During each visit the patient is checked for the triad of symptoms, but she remained symptom free and is able to do all her activities of daily living.

\section{DISCUSSION}

Glomus tumours are rare, benign, vascular neoplasms arising from glomus body which is a contractile neuromyoarterial structure found in the reticular dermis. Glomus body consists of afferent arteriole, anastomotic vessel known as SucquetHoyer Canal, primary collecting vein, intraglomerular reticulum and capsular portion. ${ }^{1}$ This structure controls blood pressure and temperature by regulating blood flow in the cutaneous vasculature. $2,3,4$

Hyperplasia in any of these parts can lead to a tumour formation. Although, this tumour can be found anywhere in 
the body, most common site of its occurrence is distal phalanx of the fingers, especially in the subungual region. 5 Though this is true in case of female population, males often have these tumours in other parts of the body. ${ }^{6}$

In general there are two types of glomus tumours, namely solitary and multiple. Solitary glomus tumours are more common, while multiple glomus tumours rarely occur in the digits. ${ }^{6}$ Multiple glomus tumours have been found simultaneously with type 1 neurofibromatosis and are often painless, making them harder to diagnose correctly. ${ }^{6}$

Magnetic resonance imaging (MRI) is an excellent imaging modality in the detection of glomus tumour and also in delineating its anatomical details such as size and location. ${ }^{7}$ Complete surgical excision of the tumour is the recommended treatment to reduce the chance of recurrence. 8 Glomus tumours account for $1 \%-5 \%$ of soft tissue tumours of the hand and $75 \%$ of them are subungual in location. The aetiology of glomus tumours is unknown and it may be related to sex, age, trauma or inheritance. Some authors have proposed that a weakness in the structure of a glomus body could lead to reactive hypertrophy after trauma. ${ }^{6}$ Researchers recently reported that a familial variant of glomus tumour had been linked to chromosome 1p21-22 and involved truncating mutations in the glomulin gene, which encoded a 68-kDa protein with unknown function. ${ }^{9,10}$ In addition to the classical triad of presentation, three useful clinical tests are helpful in diagnosing these tumours. Love's sign refers to severe localised tenderness elicited on applying pressure with a pinhead along with relief of pain when the pressure is removed. Hildreth's test is performed by elevating the patient's arm to exsanguinate it. A tourniquet is placed over arm and inflated to $250 \mathrm{mmHg}$. This causes reduction or abolition of lesional pain and tenderness. The test is positive when releasing the cuff. It causes a sudden return of pain. Almost $4-50 \%$ recurrence rate after the surgical excision is noted in the literature. While 'early recurrence' which is more common is thought to be a result of incomplete excision ${ }^{11}$ or to the presence of a second tumour that was not previously diagnosed and excised during the initial operation. ${ }^{11}$ 'Late recurrence' is attributed to the development of a new lesion at or near the excision site.

The probability of recurrence is higher in case of subungual tumours ${ }^{12}$ and this can be attributed to the operative approach and failure to locate the lesion intraoperatively as well as the surgeon's tendency to excise the matrix tissue more conservatively to avoid nail plate deformities in the post-operative period. The tumour is to be approached preferably with operative microscope or with loupe enhancement. Large incisions may complicate to large postoperative scars, paraesthesias secondary to more injury to small nerve branches and also to nail dystrophy. ${ }^{13}$

The skin coloured tumours in contrast to the classical red, blue or purple glomus tumours are difficult to delineate clearly during the surgery. Moreover, their margins are harder to demarcate properly. ${ }^{4}$ These facts are attributable to their incomplete excision, increasing the chance of recurrence. ${ }^{14}$ Foucher et al in their study reported $7 \%$ recurrence ( 4 cases) after three to five years. Heim and Hanggi in their series showed that the number of patients with early recurrence was nearly equal to the number of patients with delayed recurrence with a slight predominance of early recurrences (54\%).

\section{DISCUSSION OF MANAGEMENT}

Several measures have been recommended to ensure the complete excision and to lower the chances of recurrence. Skin-coloured tumours should be dissected layer by layer including the entire capsule. ${ }^{1}$ Microscopic monitoring 10 or intraoperative ultrasound may also be useful for ensuring adequate resection. A double tourniquet exsanguination procedure (one at mid-arm level and the other at the base of the digit) has been proposed to better visualise the tumour intraoperatively. According to the authors, none of their patients experienced recurrence of the symptoms during the follow-up period. ${ }^{4}$ In general, if the symptoms of glomus tumours persist for more than 3 months, re-exploration of the affected area and repeat imaging should be done. ${ }^{15}$ In our experience recrudescence syndrome (CRPS), which we ruled out in our patient.

\section{CONCLUSION}

Different surgeons may have different choices and may prefer one approach over the other depending on the anatomical location of the tumours. Complete surgical excision is mandatory to get complete relief of symptoms and to avoid recurrence. Even after complete clearance, the recurrence of tumour either early or late is always a possibility. We presented this patient for the very late recurrence ( $>8$ years), which was found to be due to growth of new tumour.

\section{REFERENCES}

[1] Drape JL, Idy-Peretti I, Goettmann S, et al. Subungual glomus tumours: evaluation with MR imaging. Radiology 1995;195(2):507-15.

[2] Shin DK, Kim MS, Kim SW, et al. A painful glomus tumor on the pulp of the distal phalanx. J Korean Neurosurg Soc 2010;48(2):185-7.

[3] Kale SS, Rao VK, Bentz ML. Glomus tumour of the index finger. J Craniofac Surg 2006;17(4):801-4.

[4] Bhaskaranand K, Navadgi BC. Glomus tumour of the hand. J Hand Surg Br 2002;27(3):229-31.

[5] Al-Qattan MM, Al-Namla A, Al-Thunayan A, et al. Magnetic resonance imaging in the diagnosis of glomus tumours of the hand.J Hand Surg Br 2005;30(5):535-40.

[6] Samaniego E, Crespo A, Sanz A. Key diagnostic features and treatment of subungual glomus tumor. Actas Dermosifiliogr 2009;100(10):875-82.

[7] Takemura N, Fujii N, Tanaka T. Subungual glomus tumor diagnosis based on imaging. J Dermatol 2006;33(6):389-93.

[8] Kim DH. Glomus tumor of the finger tip and MRI appearance. Iowa Orthop J 1999;19:136-8.

[9] Boon LM, Brouillard P, Irrthum A, et al. A gene for inherited cutaneous venous anomalies ("glomangiomas") localizes to chromosome 1p2122. Am J Hum Genet 1999;65(1):125-33.

[10] Brouillard P, Ghassibe M, Penington A, et al. Four common glomulin mutations cause two-thirds of glomuvenous malformations ("familial glomangiomas"): evidence for a founder effect. J Med Genet 2005;42(2):e13. 
[11] Lin YC, Hsiao PF, Wu YH, et al. Recurrent digital glomus tumor: analysis of 75 cases. Dermatol Surg 2010;36(9):1396-400.

[12] Moon SE, Won JH, Kwon OS, et al. Subungual glomus tumour: clinical manifestations and outcome of surgical treatment. J Dermatol 2004;31(12):993-7.
[13] Carroll RE, Berman AT. Glomus tumours of the hand: review of the literature and report on twenty-eight cases. J Bone Joint Surg Am 1972;54(4):691-703.

[14] Lee W, Kwon SB, Cho SH, et al. Glomus tumor of the hand. Arch Plast Surg 2015;42(3):295-301.

[15] Koc O, Kivrak AS, Paksoy Y. Subungual glomus tumour: magnetic resonance imaging findings. Australas Radiol 2007;51(Spec No.):B107-B9. 